\title{
The Interaction of Photoperiod and Temperature in Diapause Timing: A Copepod Example
}

\author{
NELSON G. HAIRSTON, JR., AND COLLEEN M. KEARNS \\ Section of Ecology and Systematics, Cornell University, Ithaca, New York 14853
}

\begin{abstract}
In many organisms, photoperiod and temperature are thought to be the most significant token cues for seasonally timed life history events, including diapause in arthropods. A common pattern in many species of terrestrial insects and several copepod specics is the existence of a critical daylength on one side of which the animals do not enter diapause and on the other side of which they do. Temperature plays a secondary role as modifier of the critical daylength. In some species, however, including the freshwater copepod Diaptomus sanguineus, the fraction of females making subitaneous eggs (eggs that hatch immediately) undergoes a very gradual transition as daylength changes over the natural range of photoperiods experienced in nature. Here we show that temperature is as important as photoperiod in cuing diapause timing in a population of $D$. sanguineus living in Bullhead Pond, Rhode Island. When ecologically relevant photoperiod and temperature cues are provided in the laboratory, the copepods rapidly switch from producing subitaneous eggs to producing diapausing eggs in a way that is typical of the seasonal switch seen in the pond. We provide a graphical model that illustrates how copepod sensitivities to photoperiod and temperature interact to produce an abrupt transition, and we discuss how natural selection should act on $D$. sanguineus diapause response to produce the variation in diapause timing seen within and between natural populations.
\end{abstract}

\section{Introduction}

An organism that times its life history to seasonal variations in its habitat must be able to detect some component of the environment that indicates time of year. To this end, many plants and animals perceive and respond to daylength (or change in daylength) as a cue for

Received 6 January 1995; accepted 4 May 1995. such phenological events as leafing-out, flowering, and seed set in plants (Harper, 1977; Begon et al., 1990), diapause and dispersal in insects (Tauber et al., 1986), and hibernation, molting, or migration in various vertebrates (Hairston, 1994). Other features of the environment (e.g., temperature, resource availability; Danilevskii, 1965; Tauber et al., 1986) can also play a role, but are typically thought to be less important because they are less reliable seasonal indicators. For example, photoperiod is the most common environmental factor cuing the onset of diapause in temperate-zone insect populations, and temperature is typically seen as one of several possible modifiers of the photoperiod response (Lees, 1955; Danilevskii, 1965; Beck, 1980; Tauber et al., 1986). A common pattern for insects that overwinter in diapause is response to a critical photoperiod below which essentially all individuals in a population enter diapause and above which no individuals enter diapause (e.g., Kogure, 1933; Tauber and Tauber, 1981, Tauber $e t$ al., 1986). Temperature affects the timing of diapause by altering the critical photoperiod: as temperature declines, the photoperiod that induces diapause increases (Danilevskii, 1965; Tauber et al., 1986). Other effects of temperature on diapause induction in insects include determination of whether any photoperiod response exists and alteration of photoperiod responses due to changes in temperature or due to diel thermopcriod (Tauber et al., 1986; Eizaguirre et al., 1994).

The reason typically given for photoperiod primacy is that daylength is the most reliable predictor of seasonal changes, and so most insects living in seasonal environments have evolved a means of sensing this cue (Lees, 1955; Tauber et al., 1986). This argument holds especially true for terrestrial habitats in which brief periods of unseasonable warming or cooling could send a false signal about time in the season. In contrast, animals living in large-volume aquatic habitats (lakes and the oceans) are buffered from short-term temperature fluctuations by the 


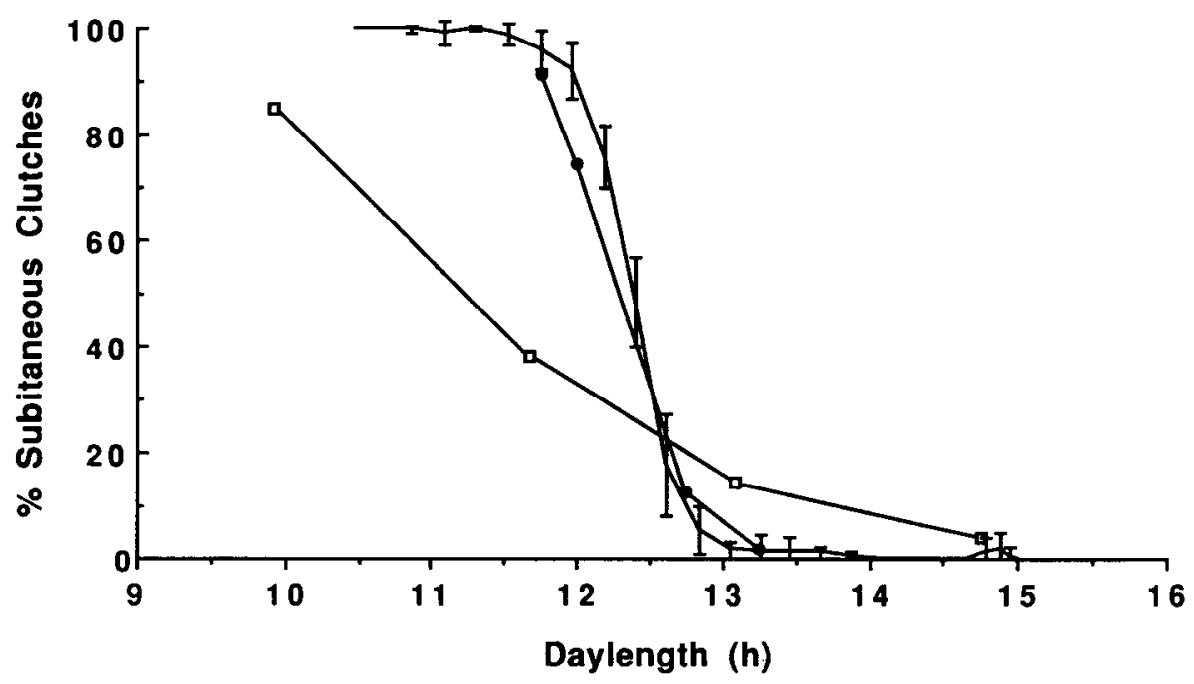

Figure 1. The timing of the switch from production of subitaneous (immediately hatching) eggs to diapausing eggs by Diaptomus sanguineus from Bullhead Pond, Rhode Island. The continuous line connecting error bars shows the mean trajectory over 9 years $( \pm 95 \% \mathrm{CI})$ for copepods in the lake, expressed as a function of photoperiod on the date that the animals were collected. The line connecting individual open data points shows the photoperiod response of females reared in the laboratory at $9^{\circ} \mathrm{C}$ (from Hairston and Olds, 1986). The line connecting closed data points shows the photoperiod response of females reared at the temperatures prevailing at the daylengths indicated (this study).

thermal inertia of water. The temperature of the medium in which they live is a more reliable indicator of the passing of the seasons than is the case on land. We might expect, then, that temperature plays a more significant role in regulating timing of diapause in aquatic animals than in their terrestrial counterparts. Among pelagic copepods, significant temperature modification of photoperiod response has been found in every instance investigated, both for cyclopoid copepods with a late-instar diapause (Watson and Smallman, 1971; Alekseev, 1990) and for calanoid copepods with egg diapause (Marcus, 1982; Walton, 1985; Hairston et al., 1990; Ban, 1992). Furthermore, Alekseev (1990) has pointed out that the effect of temperature in delaying critical photoperiod is about twice as great in pelagic copepods $\left(0.65\right.$ hours per $\left.\mathrm{C}^{\circ}\right)$ as it is in terrestrial insects $\left(0.3\right.$ hours per $\left.\mathrm{C}^{\circ}\right)$.

An enhanced effect on critical photoperiod is only one way in which temperature might be expected to influence the timing of diapause. In some species, diapause response to changing photoperiod can be gradual rather than a distinct threshold (Tauber et al., 1986). In this instance the temperature-photoperiod interaction must be somewhat different. An opportunity to explore such an interaction was presented by the data available on the timing and control of diapause in a population of Diaptomus sanguineus, a small ( $c$ a. $1 \mathrm{~mm}$ ), herbivorous, obligately sexual, freshwater copepod. This population is found in Bullhead Pond, a small Rhode Island lake that has a surface area of 2.4 ha and a maximum depth of $4 \mathrm{~m}$. While active during winter these copepods make subitaneous (immediately hatching) eggs (Hairston and Munns, 1984); in early spring they switch to making diapausing eggs, and they continue to do so until they are eliminated in late spring or early summer by sunfish predation. Nine years of data on the timing of the switch to diapause show that most females make the transition during a relatively brief 3-week period between 10 March and 10 April (Fig. 1). The timing of the switch is apparently an adaptation to avoid an annual springtime increase in fish predation (Hairston and Munns, 1984; Hairston and Walton, 1986; Hairston and Dillon, 1990). The phenological pattern shown in Figure 1 looks superficially like a typical critical photoperiod response. However, when the copepods are reared in the laboratory at a range of photoperiods, and at a single water tempcrature $\left(9^{\circ} \mathrm{C}\right)$ approximating that in the lake at the time of the switch to diapause, the transition from production of subitaneous eggs to diapausing eggs is very gradual (Fig. 1; Hairston and Olds, 1986). This experiment suggests that the copepods in the lake require a more complex signal than photoperiod alone to achieve not only the appropriate mean timing, but also the observed rate, of transition from subitaneous to diapausing eggs.

In laboratory and field studies of $D$. sanguineus, Hairston et al. (1990) showed that temperature has a striking effect on the timing of diapause, but their data are inadequate to reveal the nature of the temperature-photoperiod interaction in cuing diapause timing. Here we provide evidence that temperature and photoperiod acting together are sufficient to effect the rapid transition, as ob- 
served in Bullhead Pond, from subitaneous to diapausing eggs. We suggest a graphical depiction of the $D$. sanguineus diapause response that illustrates how its graded reaction to photoperiod alone can result in a distinct seasonal phenology when combined with temperature. The resulting model is intented as a description of the interaction of the two cues in effecting diapause timing, not as a decper mechanistic explanation of its physiological basis.

\section{Materials and Methods}

Our objective was to test the hypothesis that photoperiod and temperature are together sufficient to cue $D$. sanguineus to make subitaneous or diapausing eggs in a pattern consistent with the seasonal phenology observed in Bullhead Pond. For testing, we chose four photoperiodtemperature combinations that span the range of dates at which copepods in the lake switched between the two egg types. Our choice of conditions was based on the average distribution of switch dates in Bullhead Pond for 9 years (Fig. 1; Hairston, 1987; Hairston and De Stasio, 1988; Hairston, unpub. data), and lie \pm 1.5 and \pm 2.5 standard deviations from the mean switch date ( $=$ Julian day 85 , $26 \mathrm{March}$ ). The standard deviation of switch date is about 7 days (Hairston and Dillon, 1990), so temperature and photoperiod conditions mimicked Julian days 67.5 (8 March), 74.5 (15 March), 95.5 (5 April), and 102.5 (12 April). Tcmperatures at these times were established using averages of 11 years of in situ pond measurements (using linear extrapolation between measurement dates), and these values were paired with the photoperiods obtained from standard tables. Photoperiod-temperature combinations $\left(\mathrm{L}: \mathrm{D} \times{ }^{\circ} \mathrm{C}\right)$ were set up in four controlled environment chambers as follows: 11.75:12.25 $\times 4.3$, 12.00:12.00 × 6.0, 12.75:11.25 × 8.0, and 13.25:10.75 $\times 10.5$. Photoperiods were established at the $15-\mathrm{min}$ increment nearest to that for the chosen date, with illumination provided by daylight fluorescent lamps (17-38 $\mu \mathrm{mol} \cdot \mathrm{s}^{-1} \cdot \mathrm{m}^{-2}$ depending upon location within the growth chamber); temperatures were maintained $\pm 0.5 \mathrm{C}^{\circ}$.

Live fifth-instar copepodids of $D$. sanguineus were collected from Bullhead Pond on 2 March 1993. We mated 144 females in 125-ml glass jars (one female and two males per jar) at 8:16 L:D photoperiod and $4.8^{\circ} \mathrm{C}$ (i.e., shortday and cold conditions to ensure that all clutches produced were subitaneous; see Hairston and Olds, 1986, 1987). The copepods were fed laboratory-cultured Chlamydomonas sp. every few days. From these matings we obtained 121 ovigerous females over a period of 17 days. An additional 82 ovigerous females were obtained over the same time period from the stock 20-1 carboy of copepods in which the plankton were transported from Bullhead Pond. As egg-carrying females were found, they were distributed evenly among the four environmental treatments. When egg clutches hatched, the nauplii were placed in 250-ml glass jars, one family per jar, and again fed Chlamydomonas. As these animals reached copepodid stage, their diet was supplemented with Euglena gracilis. Mature males and females were taken from separate familics within cach environmental treatment and mated as previously described. Individual ovigerous females from these laboratory-reared cultures were isolated in 7-ml wells of 12-well plastic tissue culture plates and monitored daily for hatching. Based on established procedure (Hairston and Munns, 1984; Hairston and Olds, 1984, 1986), eggs hatching within 2 weeks (warm temperatures) or 4 weeks (cold temperatures) of laying were scored as subitaneous, and those that had not hatched by this time were scored as diapausing eggs.

\section{Results}

In each of the four environmental conditions, between 207 and 356 female copepods were reared from nauplius to ovigerous adult (Table I), although in the two lower temperature treatments a substantial fraction of the egg sacs produced were nonviable (i.e., eggs turned grey and decomposed). The fractions of egg sacs that were either subitaneous or diapausing were calculated relative to the total number of viable sacs (Table I). Because the nature of the nonviable egg sacs could not be determined, we make the null assumption that viability was independent of egg type.

A plot of percent subitaneous clutches produced at each of the treatment conditions as a function of daylength (Fig. 1) shows that photoperiod and temperature together produce a diapause phenology remarkably similar to that observed in the wild. The fit is much better-both in mean timing and in the rapidity of the population switch to diapause-than that found previously for photoperiod alone (Hairston and Olds, 1986).

\section{Table I}

Photoperiod and temperature combinations under which diapause response was determined for Diaptomus sanguineus (reasons for condition chosen given in the text), the total number of egg clutches produced (one clutch per female), the number of viable clutches, and the percentages of viable clutches that were either subitaneous or diapausing

\begin{tabular}{|c|c|c|c|c|c|}
\hline \multicolumn{2}{|c|}{ Treatment } & \multirow{2}{*}{\multicolumn{2}{|c|}{ Clutches }} & \multirow{3}{*}{$\begin{array}{c}\% \\
\text { Subitaneous } \\
\text { clutches }\end{array}$} & \multirow{3}{*}{$\begin{array}{c}\% \\
\text { Diapausing } \\
\text { clutches }\end{array}$} \\
\hline \multirow{2}{*}{$\begin{array}{c}\text { Daylength } \\
\text { (h) }\end{array}$} & \multirow{2}{*}{$\begin{array}{l}\text { Temp. } \\
\left({ }^{\circ} \mathrm{C}\right)\end{array}$} & & & & \\
\hline & & Total & Viable & & \\
\hline 11.75 & 4.3 & 356 & 265 & 91.3 & 8.7 \\
\hline 12.00 & 6.0 & 293 & 121 & 74.7 & 25.6 \\
\hline 12.75 & 8.0 & 245 & 243 & 12.8 & 87.2 \\
\hline 13.25 & 10.5 & 207 & 203 & 2.0 & 98.0 \\
\hline
\end{tabular}




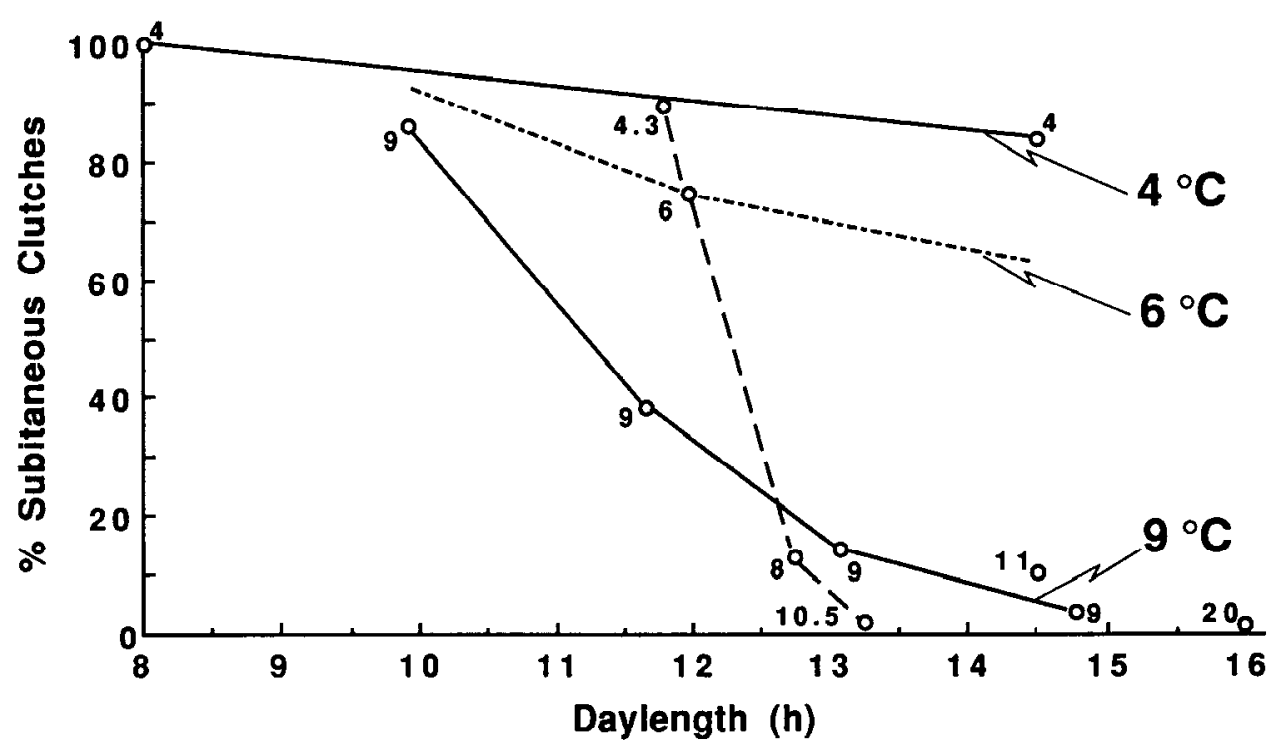

Figure 2. The fraction of subitaneous eggs (versus diapausing eggs) produced by Diaptomus sanguineus when reared in the laboratory at different combinations of photoperiod and temperature. The data, taken from three previous studies (Hairston and Olds, 1986, 1987; Hairston et al., 1990) and the current investigation, show distinct diapause responses to daylength at different temperatures. Solid lines connect values from experiments at equal temperatures $\left(4^{\circ} \mathrm{C}\right.$ and $\left.9^{\circ} \mathrm{C}\right)$. The dotted $6^{\circ} \mathrm{C}$ line is a hypothetical relationship based on the single $6^{\circ} \mathrm{C}$ point and the $4{ }^{\circ} \mathrm{C}$ and $9^{\circ} \mathrm{C}$ lines. The dashed line connects the four photoperiod-temperature treatments reported here and thus shows the trajectory of diapause phenology of $D$. sanguineus as photoperiod and temperature increase during spring in Bullhead Pond, Rhode Island.

\section{Discussion}

For Diaptomus sanguineus in Bullhead Pond, the gradual effect of photoperiod at a constant temperature (Hairston and Olds, 1986, see Fig. 1) is converted into a discrete seasonal timing of diapause by the addition of a thermal cue. Similar to our result, those of Marcus (1982) show a gradual shift from subitaneous to diapausing egg production as a function of photoperiod for the calanoid copepod Labidocera aestiva, despite a seasonal transition to diapause in nature that is quite discrete (Marcus, 1979). In her study, however, temperature had a weaker effect on the diapause response than we have observed for $D$. sanguineus. Our result contrasts with the photoperiod-dominated pattern seen in many insect species (Danilevskii, 1965; Tauber et al., 1986) and in several previous studies of diapause in pelagic copepods. Photoperiod plays a primary role in the switch to diapausing eggs in the calanoid copepod Eurytemora affinis (Ban, 1992) and in the lateinstar diapause of the cyclopoid copepods Diacyclops navus (Watson and Smallman, 1971) and Metacyclops minutus (Alekseev, 1990). Copepod density can also act as a significant modifier of the photoperiod cue ( $E$. affinis, Ban, 1992; M. minutus, Alekseev, 1990); and in Diaptomus birgei, photoperiod is only a secondary factor in cuing diapause (Walton, 1985).

How does temperature sensitivity convert a gradual photoperiod response into a relatively discrete seasonal switch to diapause for the $D$. sanguineus population? An answer emerges when we plot, in a single figure (Fig. 2), all of the available data for $D$. sanguineus diapause response at a range of photoperiods and temperatures (Hairston and Olds, 1986, 1987; Hairston et al., 1990; this study). In this plot, the slope of the line relating the percentage of subitaneous clutches to the daylength is much shallower at $4^{\circ} \mathrm{C}$ than at $9^{\circ} \mathrm{C}$. The single data point at $6^{\circ} \mathrm{C}$ is intermediate between these two lines, and we conjecture that a $6^{\circ} \mathrm{C}$ line would have an intermediate slope. Data points at higher temperatures (i.e., $8-11^{\circ} \mathrm{C}$ ) are variable, but uniformly give low values for the percentage of subitaneous clutches. The dashed line in Figure 2 shows what happens as both temperature and photoperiod change early in the seas $\lrcorner \mathrm{n}$ in Bullhead Pond. At short photoperiods, when water temperatures are $4^{\circ} \mathrm{C}$ or below, the copepods make subitaneous eggs. As spring comes on, not only does photoperiod increase, but so does temperature; thus the appropriate daylength-response shifts from the $4^{\circ} \mathrm{C}$ line to the $6^{\circ} \mathrm{C}$ line to the $9^{\circ} \mathrm{C}$ line, and so on. The result is the relatively discrete seasonal switch to production of diapausing eggs seen in Bullhead Pond. Note also that the data in Figure 2 could be expressed equally well by plotting the percentage of subitaneous clutches against temperature, with lines of equal photoperiod radiating from the upper left-hand corner. The photoperiod-temperature interaction would be still apparent. 
Our depiction of the response of $D$. sanguineus to combined photoperiod and thermal cues (Fig. 2) illustrates only the phenotypes expressed by the copepods when exposed to environments of differing photoperiod and temperature combinations. Behind this response surface lies the physiological mechanisms by which the copepods detect daylength (or nightlength) and temperature and then react by producing the appropriate egg type.

Two alternative photoperiodic clock mechanisms have received substantial attention in the entomological literature. The circadian oscillator model posits an internal pacemaker of intrinsic period, which is then either compared (physiologically) to the environment (i.e., photoperiod) or drives other, "slave," oscillators whose phases are differentially altered by the environment (Pittendrigh, 1981; Saunders, 1982; Gillanders and Saunders, 1992). The hourglass model hypothesizes the production of some chemical substance that accumulates incrementally during the dark (or the light) phase of a light-dark cycle, up to some critical threshold (Lees, 1973; Skopik and Bowen, 1976; Veerman et al., 1988). Some recent studies have emphasized models that have an underlying oscillator but can exhibit hourglass-like behavior (e.g., Vas Nunes et al., 1991). In addition to providing a mechanism for critical photoperiod response, each model provides a mechanism for the influence of temperature in shifting critical photoperiod earlier or later in the season (Pittendrigh et al., 1991; Vas Nunes et al., 1991; Kimura and Masaki, 1993). The conversion, in $D$. sanguineus, of a graded photoperiod response to a much sharper seasonal phenology by the addition of a thermal cue results simply from a rightward shift (towards longer photoperiods) of the diapause response curve under low temperatures and a leftward shift (towards shorter photoperiods) under high temperatures (Fig. 3; explained in detail below). Because both clock models could, in principle, accommodate this behavior, the data presented here do not permit us to distinguish between the two alternatives. Nevertheless, experiments designed to determine the photoperiodic clock mechanism in this copepod should provide essential clues for understanding both the range of expression of diapause response by $D$. sanguineus to different environments and the possible constraints on the genetic covariance structure of sensitivity to photoperiod and thermal cues (i.e., how selection on copepod sensitivity of diapause expression to photoperiod might influence trait sensitivity to temperaturc).

The pattern of photoperiod-temperature response proposed here does not in fact differ radically from typical thermal alteration of critical photoperiod. Figure $3 \mathrm{~A}$ shows a family of hypothetical critical daylength responses modified by temperature that would produce a spring switch from production of subitaneous to diapausing eggs by a pelagic copepod species. If the lake temperature in- creased with lengthening photoperiod according to the patterns listed in Figure 3E, the copepods would make subitaneous eggs until the threshold photoperiod and temperature combination that induced a complete switch to diapausing eggs was reached. Figure 3B shows critical response curves more typical of many insect species in which the transition to diapause is not rectilinear but somewhat graded, with a thermal effect on critical photoperiod of $0.3 \mathrm{~h}$ per $\mathrm{C}^{\circ}$ (c.f., Danilevskii, 1965, pp. 114$115)$. Tracking the environment of Figure $3 \mathrm{E}$ produces a seasonal switch to diapause more rapid than that seen along any constant temperature line, though not as rapid as that seen in Figure 3A. In contrast to these two patterns, the photoperiod response lines for different temperatures in Figure 2 radiate from 100\% subitaneous clutches at short photoperiod (i.e., there is no temperature effect at short daylength). Suppose now that these lines of constant temperature reconverge at long photoperiods on $0 \%$ subitaneous clutches ( $100 \%$ diapause), as illustrated in Figure 3C. Tracking the Figure 3E environment again produces a seasonal switch to diapause, just as seen in Figure 2. The differences between each of these three patterns lie in the steepness of the slopes of the photoperiod responses. It is not difficult, however, to envision any one pattern being derived from one of the others through a simple change in how rapidly diapause responds to photoperiod at each temperature.

A gradual transition from production of subitaneous eggs to diapausing eggs in a single population implies that individual females must respond differently to any given photoperiod-temperature combination (i.e., some fraction make subitaneous eggs while the others make diapausing eggs). For $D$. sanguineus, we know that there is significant heritable variation for diapause response at $13 \mathrm{~h}$ of light and $9^{\circ} \mathrm{C}$ in the laboratory (Hairston and Dillon, 1990). If the model in Figures 2 and $3 \mathrm{C}$ is an accurate representation of the sensitivity of the copepods' diapause response to temperature and photoperiod, it provides a means of envisioning how natural selection might act on this genetic variation to alter the timing of diapause in natural populations. For example, $500 \mathrm{~m}$ from Bullhead Pond lies Little Bullhead Pond. In 1979, the D. sanguineus population in this pond switched to diapause in late March, the same time as the population in Bullhead Pond. In 1981, a drought dried Little Bullhead Pond and killed all of the fish, thus removing the principal selection force maintaining the March diapause date. The pond refilled in 1982, and by 1983 the mean timing of diapause had moved to late April, apparently as a rcsponse to the altered selection regime (Hairston and Walton, 1986; Hairston and De Stasio, 1988). Bullhead Pond, which is deeper than Little Bullhead Pond, did not dry, no fish were killed, and the timing of diapause in that population changed little between 1979 and 1983 (Hairston and Walton, 1986; 

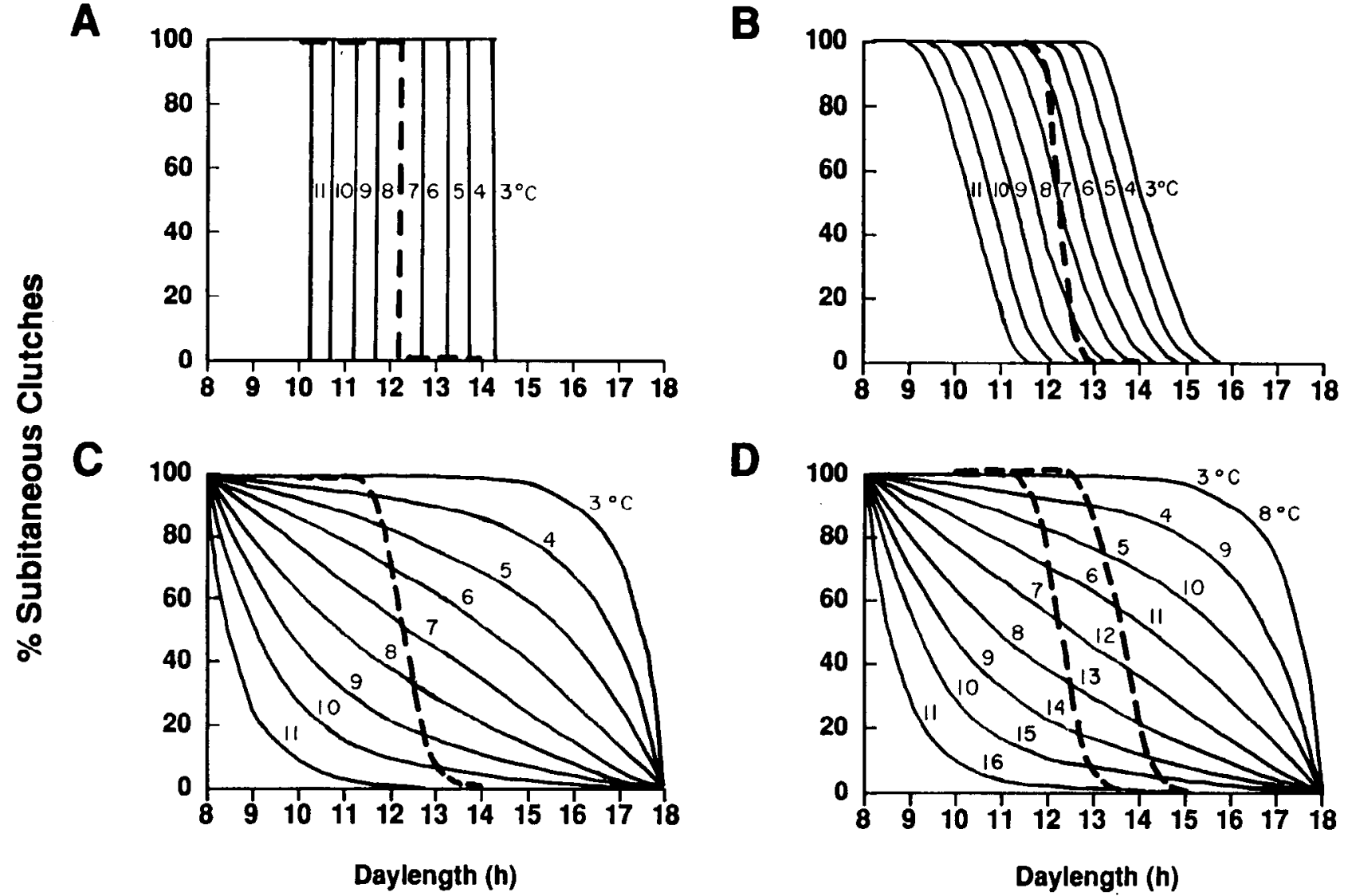

$\mathbf{E}$

Daylength (h)

\begin{tabular}{lcccccccccccccc}
\hline Date & Feb & 1 & 10 & 21 & Mar & 6 & 18 & 29 & Apr & 10 & 20 & May & 5 & 20 \\
\hline Daylight (h) & 10 & 10.5 & 11 & & 11.5 & 12 & 12.5 & & 13 & 13.5 & & 14 & 14.5 \\
Temp $\left({ }^{\circ} \mathrm{C}\right)$ & & 3 & 3 & 3 & & 4 & 6 & 8 & & 10 & 11 & & 13 & 18 \\
\hline
\end{tabular}

Figure 3. Three patterns of springtime diapause responses under varying combinations of photoperiod and temperature. (A) Strict critical-photoperiod response with thermal effect. (B) Critical-photoperiod response with a graded transition from $100 \%$ non-diapause to $100 \%$ diapause covering a photoperiod range of about $2 \mathrm{~h}$ and a temperature delay of $1.5 \mathrm{~h}$ per $1{ }^{\circ} \mathrm{C}$, as is typical of many insects. (C) Gradual transition from $100 \%$ non-diapause to $100 \%$ diapause with lengthening daylength as seen for D. sanguineus (Fig. 2), but with the added assumption that all animals produce diapausing eggs at long photoperiods independent of temperature. (D) Same graph as in C, but with response line relabeled to show the effect of selection for later diapause. (E) Springtime pattern of increasing photoperiod and temperature typical of Bullhead Pond, Rhode Island (see Table I). These values are used in A, B, and C to illustrate projecled diapause phenologies. In each case the mean switch to diapause occurs at $12.3 \mathrm{~h}$ daylength and $7^{\circ} \mathrm{C}$.

Hairston and Dillon, 1990). What features of the photoperiod and temperature responses of the Little Bullhead Pond populations were altered by selection to produce the change in diapause phenology? For diapause timing to be heritable, the hypothetical temperature-specific photoperiod-response lines in Figures 2 and $3 \mathrm{C}$ must vary depending upon genotype. That is, for some genotypes the lines lie above the population mean, and for others the lines lie below the mean. Directional selection for later diapause would simply move the population mean re- sponse lines upward (as in Figure 3D). The effect is a joint one on both thermal and photoperiodic responses of the copepods: at a given temperature, the slope of the response to change in daylength is shallower, but also, at a given photoperiod, the position of each of the isothermal lines is raised. With the new temperature-specific photoperiodresponse lines, the timing of diapause shifts to later in the season (Figure 3D).

Populations of $D$. sanguineus living in different lakes and ponds exhibit both distinct photeperiod responses 
under controlled laboratory conditions (Hairston and Olds, 1986, 1987) and distinct seasonal diapause phenologies in the field (Hairston and Olds, 1984; Hairston et al., 1985). Both the mean timing of diapause and the temporal pattern of the switch from subitaneous to diapausing eggs vary between populations. In ephemeral pools, water depths and temperatures fluctuate depending upon local rainfall, leading to a decoupling of temperature and photoperiod as predictors of time in the season. Here, $D$. sanguineus can show late-season reversals to subitaneous egg production (Hairston and Olds, 1987). The graphical model developed here provides a framework for investigating the genetic covariance structure underlying such interpopulation variation in diapause responses to photoperiod and to temperature, and how this structure differs to produce the variety of diapause phenologies observed in nature.

\section{Acknowledgments}

We thank C. Tauber, M. Tauber, S. Ellner, L. Polishchuck, and N. Hairston, Sr., for helpful discussions, and $\mathrm{K}$. Batson for technical assistance. This research was supported by National Science Foundation grant BSR9118894 to $\mathrm{NGH}$ and S. Ellner.

\section{Literature Cited}

Alekseev, V. 1990. Crustaceans Diapause: Ecological and Physiological Aspects. Nauka, Moscow. 143 pp.

Ban, S. 1992. Seasonal distribution, abundance and viability of diapause eggs of Eurytemora affinis (Copepoda: Calanoida) in the sediment of Lake Ohnuma, Hokkaido. Bull. Plankton Soc. Jpn. 39: 41-48.

Beck, S. 1980. Insect Photoperiodism. Academic Press, New York. $387 \mathrm{pp}$.

Begon, M., J. L. Harper, and C. R. Townsend. 1990. Ecology: Individuals, Populations and Communities. Blackwell, Boston. 945 pp.

Danilevskii, A. S. 1965. Photoperiodism and Seasonal Development of Insects. Oliver and Boyd, Edinburgh. $283 \mathrm{pp}$.

Eizaguirre, M., C. López, L. Asín, and R. Albajes. 1994. Thermoperiodism, photoperiodism and sensitive stage in the diapause induction of Sesamia nonagrioides (Lepidoptera: Noctuidae). J. Insect Physiol. 44: 113-119.

Gillanders, S. W., and D.S. Saunders. 1992. A coupled pacemaker-slave model for the insect photoperiodic clock: interpretation of ovarian diapause data in Drosophila melanogaster. Biol. Cybern. 67: 451459.

Hairston, N. G., Jr. 1987. Diapause as a predator-avoidance adaptation. Pp. 281-290 in Predation: Direct and Indirect Impacts on Aquatic Communities, W. C. Kerfoot and A. Sih, eds. Univ. Press of New England, Hanover, $\mathrm{NH}$.

Hairston, N. G., Jr., and B. T. De Stasio, Jr. 1988. Rate of evolution slowed by a dormant propagule pool. Nature 336: 239-242.

Hairston, N. G., Jr., and T. A. Dillon. 1990. Fluctuating selection and response in a population of freshwater copepods. Evolution 44: 17961805.

Hairston, N. G., Jr., and W. R. Munns, Jr. 1984. The timing of copepod diapause as an evolutionarily stable strategy. Am Nat. 123: 733-751.

Hairston, N. G., Jr., and E. J. Olds. 1984. Population differences in the timing of diapause: adaptation in a spatially heterogeneous environment. Oecologia 61: 42-48.
Hairston, N. G., Jr., and E. J. Olds. 1986. Partial photoperiodic control of diapause in three populations of the freshwater copepod Diaptomus sanguineus. Biol. Bull. 171: 135-142.

Hairston, N. G., Jr., and E. J. Olds. 1987. Population differences in the timing of diapause: a test of hypotheses. Oecologia 71: 339-344.

Hairston, N. G., Jr., and W. E. Walton. 1986. Rapid evolution of a life history trait. Proc Natl. Acad Sci USA 83: 4831-4833.

Hairston, N. G., Jr., T. A. Dillon, and B. T. De Stasio, Jr. 1990. A field test for the cues of diapause in a freshwater copepod. Ecology 71: 2218-2223.

Hairston, N. G., Jr., E. J. Olds, and W. R. Munns, Jr. 1985. Bethedging and environmentally cued diapause strategies of diaptomid copepods. Int. Ver. Theor. Angew. Limnol. Verh. 22: 3170-3177.

Hairston, N. G., Sr. 1994. Vertebrate Zoology: An Experimental Field Approach. Cambridge Univ. Press, Cambridge. 347 pp.

Harper, J. L. 1977. Population Biology of Plants. Academic Press, New York. 892 pp.

Kimura, Y., and S. Masaki. 1993. Hourglass and oscillator expression of photoperiodic diapause response in the cabbage moth Mamestra brassicae. Physiol. Entomol. 18: 240-246.

Kogure, M. 1933. The influence of light and temperature on certain characters of the silkworm, Bombyx mori. J. Seric. Sci. Jpn. 4: 193.

Lees, A. D. 1955. The Physiology of Diapause in Arthropods. Cambridge Univ. Press, Cambridge. $151 \mathrm{pp}$.

Lees, A. D. 1973. Photoperiodic time measurement in the aphid $\mathrm{Me}$ goura viciae. J. Insect Physiol. 19: 2279-2316.

Marcus, N. H. 1979. On the population biology and nature of diapause of Labidocera aestiva (Copepods: Calanoida). Biol_Bull. 157: 297305.

Marcus, N. H. 1982. Photoperiodic and temperature regulation of diapause in Labidocera aestiva. Biol Bull. 162: 45-52.

Pittendrigh, C. S. 1981. Circadian organization and the photoperiodic phenomena. Pp. 1-35 in Biological Clocks in Seasonal Reproductive Cycles, B. K. Follett and D. E. Follett, eds. Wiley, New York.

Pittendrigh, C.S., W. T. Kyner, and T. Takamura. 1991. The amplitude of circadian oscillations: temperature dependence, latitudinal clines and the photoperiodic time measurement. J. Biol Rhuthms 6: 299313.

Saunders, D. S. 1982. Insect Clocks. 2nd ed. Pergamon Press, New York. 409 pp.

Skopik, S. D., and M. F. Bowen. 1976. Insect photoperiodism: an hourglass measures photoperiodic time in Ostrinia nubilalis. J. Comp. Physiol. 111: 249-259.

Tauber, C. A., and M. J. Tauber. 1981. Insect seasonal cycles: genetics and evolution. Ann. Rev. Ecol. Syst. 12: 281308.

Tauber, M. J., C. A. Tauber, and S. Masaki. 1986. Seasonal Adaptations of Insects. Oxford Univ. Press, New York, $411 \mathrm{pp.}$

Vas Nunes, M., R. D. Lewis, and D. S. Saunders. 1991. A coupled oscillator feedback system as a model for the photoperiodic clock in insects and mites. II. Simulations of photoperiodic responses. $J$. Theor. Biol. 152: 299-317.

Veerman, A., M. Beekman, and R. L. Veenendaal. 1988. Photoperiodic induction of diapause in the large white butterfly, Pieris brassicae: evidence for hourglass time measurement. J. Insect Physiol. 34: $1063-$ 1069.

Walton, W. E. 1985. Factors regulating the reproductive phenology of Onychodiaptomus birgei (Copepoda: Calanoida). Limnol. Oceanogr. 30: $167-179$.

Watson, N. H., and B. N. Smallman. 1971. The role of photoperiod and temperature in the induction and termination of an arrested development in two species of freshwater cyclopoid copepods. Can. J. Zool. 49: 855-862. 